“C 2017 IEEE. Personal use of this material is permitted. Permission from IEEE must be obtained for all other uses, in any current or future media, including reprinting/republishing this material for advertising or promotional purposes, creating new collective works, for resale or redistribution to servers or lists, or reuse of any copyrighted component of this work in other works." 


\title{
Direct Storage Hybrid (DSH) Inverter: A New Concept of Intelligent Hybrid Inverter
}

\author{
Ha Pham N. \\ University of Technology, Sydney \\ Email: phamngocha@ieee.org
}

\begin{abstract}
This paper proposes a new configuration of a singlephase hybrid inverter with an integrated battery energy storage, which is suitable for residential households to maximize local consumption of solar energy and thus reduce dependency on grid support. The hybrid inverter is called Direct Storage Hybrid (DSH) Inverter. A transformer-less topology such as HERIC, operating at low frequency to generate a three-level rectangular output voltage, is adopted to connect a photovoltaic (PV) panel to the load and/or the grid. A series active filter is employed to compensate the high harmonic components from the rectangular voltage and provide a sinusoidal voltage. A bidirectional dc/dc converter connects the battery to the PV panel to control the battery state of charge $(\mathrm{SoC})$ and optimize the $\mathrm{PV}$ panel operation during both off-grid and grid-connected modes. The DSH inverter can let the battery bypass the dc/dc converter and connect directly to the inverter stage, leading to a significant improvement in throughput efficiency in battery utilization. This paper discusses the operation and loss analysis of the DSH inverter in off-grid mode.
\end{abstract}

Index Terms - smart hybrid inverter, battery charger, battery storage system, throughput efficiency

\section{INTRODUCTION}

Renewable energies, like PV and wind, hold great promise as future solutions for our energy needs. However, their fluctuating nature harms electricity grids, and options that make grids smarter or improve their stability have long been research trends such as integrating battery storage solutions into existing grids to maximise the capacity, efficiency and use of renewable energies [1]-[5]. An example of this is stand-alone PV inverter or intelligent hybrid inverter with energy storage capability. An intelligent hybrid inverter stores energy only when necessary and maximizes self-consumption of PV energy. Such storage capability becomes more and more important when the price of solar energy sold to grid keeps getting cheaper [6]. Intelligent hybrid inverter is therefore predicted to be the future of PV installation, according to the French Electric Network.

There are two common configurations for the intelligent hybrid inverter. The first system consists of a PV inverter and a separated battery inverter operating in parallel. They are connected to an ac bus via a multi-winding transformer [7], [8] or transformer-less topologies [9]. The battery inverter stores the energy via the ac bus [10], [11]. The second system uses a common dc bus to link the solar panel, battery through a bidirectional dc/dc power converter and then adds a dc/ac inverter to interface with the ac grid [12]-[16]. Alternatively, uncommon configurations such as Z-source inverter [17]-[19], multi- port ac link inverter [20], or switched-battery inverter [21], [22] were also proposed. However, it is difficult to achieve a high overall efficiency with these methodologies because there are many conversion paths and/or devices needed which would introduce more losses to the whole system. More importantly, none of the existing methods is capable of providing an optimized efficient path for PV-battery-load energy flow to maximize the battery usage and achieve the best throughput efficiency. This throughput efficiency is particularly important because the battery is the most expensive component in the system.

This paper proposes a new concept of high-efficient single phase intelligent hybrid inverter called Direct Storage Hybrid (DSH) inverter with an optimal throughput path for battery energy storage. The DSH inverter is applicable to residential households to maximize the local consumption of solar energy and thus reduce the stress on grid. The DHS inverter is equipped with an integrated power management system, which optimises the battery performance in terms of operating cost, and can operate in both off-grid and grid-connected modes.

This paper presents the operation of the DSH inverter in off-grid mode and analyses its power losses to prove its superior throughput efficiency via circuit simulation. The DSH inverter has an independent battery charging path which can be optimized separately. It also has an excellent performance when discharging the battery to support the load at night. As a result, the DSH inverter can cover a wide range of operation with an expected throughput efficiency of more than $96 \%$.

\section{Circuit CONFIGURATiON}

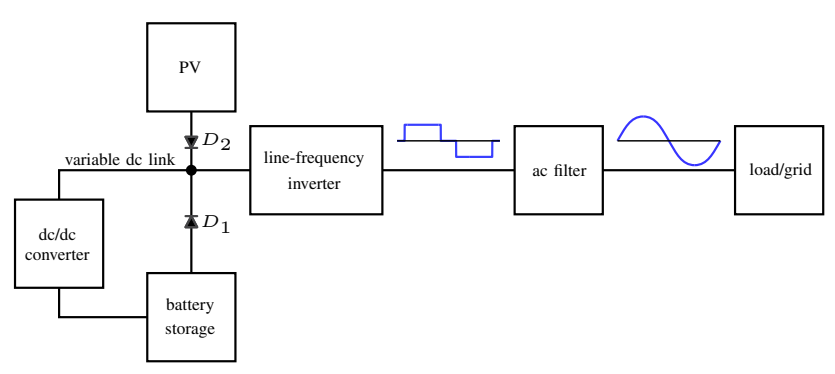

Fig. 1. General construction of the DSH Inverter.

Fig. 1 illustrates a general structure of the DSH inverter. A variable dc link is connected to a PV and a battery via diodes $D_{1}$ and $D_{2}$. A dc/dc converter (battery charger) is used to charge/discharge the battery via the dc link. When 


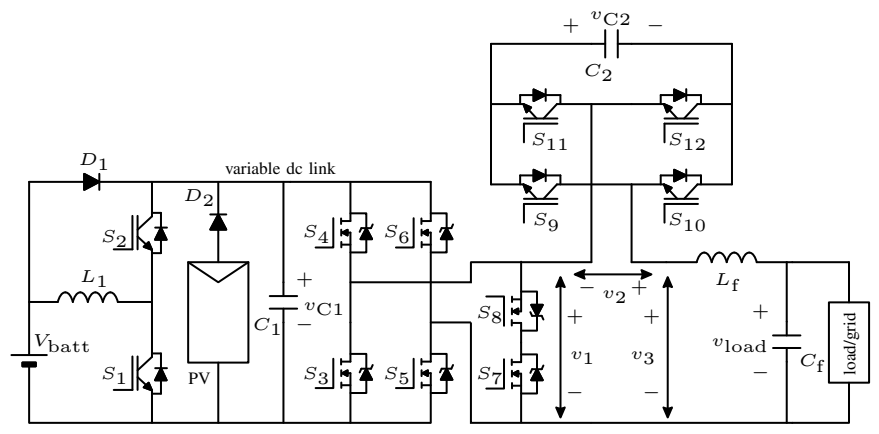

Fig. 2. Example circuit configuration of the DSH Inverter.

the PV is not operated, the battery can bypass the $\mathrm{dc} / \mathrm{dc}$ converter via diode $D_{1}$ and connect directly to the dc link. A line-frequency inverter converts the dc link to a three-level rectangular voltage. Then, an ac filter is applied in series to reshape the rectangular voltage to sinusoidal and supply the load and/or grid.

Fig. 2 shows an example circuit configuration of the proposed DSH inverter. A battery is connected to a dc link capacitor $C_{1}$ via a bidirectional dc/dc converter, e.g. a half bridge structure. The diode $D_{1}$ is used to bypass the $\mathrm{dc} / \mathrm{dc}$ converter and connect the battery directly to the inverter unit. A PV panel is connected to the same dc link capacitor via the other diode $D_{2}$ which blocks current from flowing backward. The dc/dc converter can also act as a maximum power point tracking (MPPT) device. The two diodes could be replaced by relays to reduce conduction loss. A transformer-less topology such as HERIC [23] with 6 active switches $S_{3}-S_{8}$ is used to connect the dc link capacitor $C_{1}$ to the grid, but only operated at line frequency to generate a rectangular output voltage. A series active filter with 4 high-frequency switches $S_{9}-S_{12}$ and an LC filter $\left(L_{\mathrm{f}}, C_{\mathrm{f}}\right)$ are employed to compensate the high harmonic voltages from the rectangular one [24]-[26]. The output is connected to a load and/or to an ac grid and operated in either off-grid mode or grid-connected mode.

The bidirectional dc/dc converter connects the battery to the PV panel to charge/discharge the battery and support the PV panel operations. After sunset, the battery bypasses the boost converter and connects directly to the inverter, leading to a significant improvement in throughput efficiency and reduction in operational cost of battery.

Switches $S_{3}-S_{8}$ only operate at low frequency, i.e. $50-\mathrm{Hz}$ line frequency, therefore they have negligible switching losses and can be MOSFETs to lower the conduction losses. The other switches can be IGBTs to perform switching at high frequency.

\section{OPERATING PRINCIPLE}

The operating principle of the DHS inverter is similar to that of a ZCC converter [25], but has the extra capability to connect a battery storage directly to the dc link terminals. Fig. 3 shows the theoretical waveforms in the proposed DSH inverter. To ensure a successful PWM operation in the active filter, the

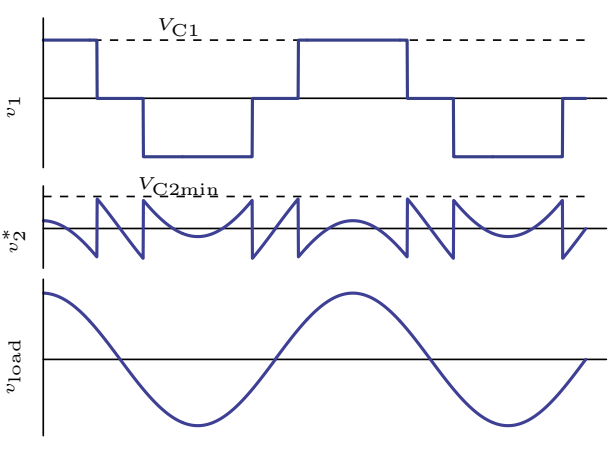

Fig. 3. Theoretical voltage waveforms of the DSH inverter.

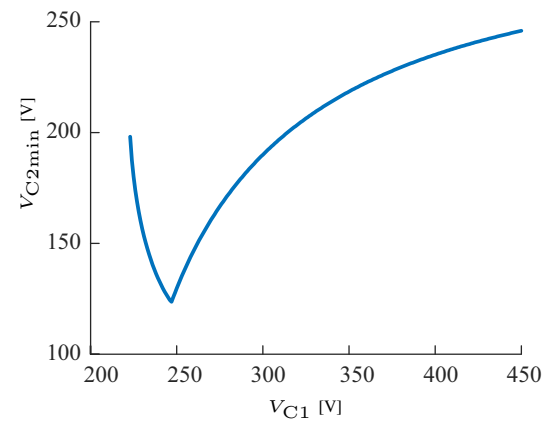

Fig. 4. Theoretical relation between input voltage $V_{\mathrm{C} 1}$ and the minimum required voltage of the capacitor $C_{2}, V_{\mathrm{C} 2 \mathrm{~min}}$.

capacitor voltage $v_{\mathrm{C} 2}$ must be higher than the maximum value of the reference voltage $v_{2}^{*}$ :

$$
v_{\mathrm{C} 2}>v_{2}^{*} \text {. }
$$

Fig. 4 illustrates a theoretical relation between $V_{\mathrm{C} 1}$ and the minimum required voltage of the capacitor $C_{2}$ in an ideal case of constant capacitor voltages. It can be seen that the minimum required capacitor voltage $V_{\mathrm{C} 2 \mathrm{~min}}$ varies under different input voltage, $V_{\mathrm{C} 1}$, from the variable dc link. The required voltage $V_{\mathrm{C} 2 m i n}$ reaches its minimum of $125 \mathrm{~V}$ at $V_{\mathrm{C} 1} \approx 250 \mathrm{~V}$. Other than that, $V_{\mathrm{C} 2 \mathrm{~min}}$ is still less than $250 \mathrm{~V}$ even when the input voltage reaches $450 \mathrm{~V}$. The reason is that the active filter only compensates a part of the rectangular output $v_{1}$. Most of the cases, this required voltage is much less than a conventional dc link voltage of solar inverter which is usually $400 \mathrm{~V}$. If a controller is installed to reduce $v_{\mathrm{C} 2}$ to the minimal requirement $V_{\mathrm{C} 2 \mathrm{~min}}$, the switching loss of the active filter will be optimized. Since the required dc voltage of the active filter is reduced, its switching loss is expected to be lower than the conventional inverter.

Considering that the DSH inverter supplies power to a load, the output ac voltage $v_{\text {load }}$ is the output of the LC filter and thus becomes sinusoidal. Its rms voltage $V_{\text {load }}=200 \mathrm{Vac}$ represents a normal grid:

$$
v_{\text {load }}=\sqrt{2} V_{\text {load }} \cos \omega t .
$$

The low frequency transformer-less inverter and the high frequency active filter are connected in cascade to form the desired sinusoidal output $v_{\text {load }}$. As shown in Fig. 3, the inverter 
outputs a 3-level rectangular output voltage $v_{1}$ with a pulse width $\delta$ under line switching frequency of $50 \mathrm{~Hz}$ :

$$
v_{1}=v_{\mathrm{C} 1} f(\delta),
$$

where $f(\delta)$ is a 3-level rectangular function given by:

$$
f(\delta)= \begin{cases}1 & ,-\delta / 2<\omega t+2 n \pi<\delta / 2 \\ -1 & ,-\delta / 2<\omega t+(2 n+1) \pi<\delta / 2, \forall n \in N \\ 0 & , \text { otherwise. }\end{cases}
$$

Since this voltage provides the power needed at the load, the fundamental rms component of $v_{1}$ must equal $V_{\text {load }}$ :

$$
V_{1 \mathrm{f}}=\frac{1}{\sqrt{2}} \int_{0}^{\frac{2 \pi}{\omega}} v_{1} \cos \omega t d t=V_{\text {load }} .
$$

Substitute (3) and (4) to (5) and assume that $v_{\mathrm{C} 1}$ is constant at its average value $V_{\mathrm{C} 1}$, we can derive the pulse width $\delta$ as

$$
\delta=\sin ^{-1} \frac{\pi V_{\text {load }}}{\sqrt{2} V_{\mathrm{C} 1}} .
$$

According to (6), the calculation of $\delta$ is only possible when

$$
V_{\mathrm{C} 1} \geq \frac{\pi}{\sqrt{2}} V_{\text {load }} \approx 223 \mathrm{~V}
$$

Fig. 4 also indicates that the minimal voltage at the PV terminal should be at least $223 \mathrm{~V}$ to keep the DSH inverter working. If the solar energy is not enough, i.e. low sunlight, the battery can provide more power to the variable dc link and keep the DSH inverter running smoothly without drawing power from the grid. It also means that the operating voltage of the battery must start from $223 \mathrm{~V}$.

In reality, the capacitor voltage $v_{\mathrm{C} 1}$ has non-negligible ripple and a controller must be implemented to compensate for that. On the other hand, the active filter has an output voltage $v_{2}$ which does not generate active power theoretically. However, due to losses in each device, the active filter capacitor voltage $v_{\mathrm{C} 2}$ degrades over times and needs to be maintained by injecting some active power to the active filter.

Assuming that the output ac current $i$ is sinusoidal with a phase difference $\phi$ compared to the output voltage $v_{\text {load }}$, the average power provided to the active filter can be calculated from its fundamental rms voltage $V_{2 \mathrm{f}}$ and the output rms current $I$ as follows:

$$
P_{\mathrm{C} 2}=-V_{2 \mathrm{f}} I \cos \phi .
$$

As shown in Fig. 3, the active filter operates at high frequency, such as $20 \mathrm{kHz}$, to avoid acoustic noise, using pulse width modulation (PWM) to create voltage $v_{2}$ with reference value $v_{2}^{*}$ which is designed to compensate the high frequency components in $v_{1}$ so that:

$$
v_{2}^{*}=v_{\text {load }}-v_{1} .
$$

As a result, their fundamental rms values follow the same relation as:

$$
V_{2 \mathrm{f}}=V_{\text {load }}-V_{1 \mathrm{f}}
$$

Substitute (10) to (8), we have

$$
P_{\mathrm{C} 2}=\left(V_{1 \mathrm{f}}-V_{\text {load }}\right) I \cos \phi .
$$

The active power $P_{\mathrm{C} 2}$ charges/discharges the capacitor $C_{2}$ and compensates the loss in the active filter. Therefore, the capacitor voltage $v_{\mathrm{C} 2}$ can be adjusted by controlling $V_{1 \mathrm{f}}$ via the pulse width $\delta$ and/or phase angle $\phi$.

\section{Control Method}

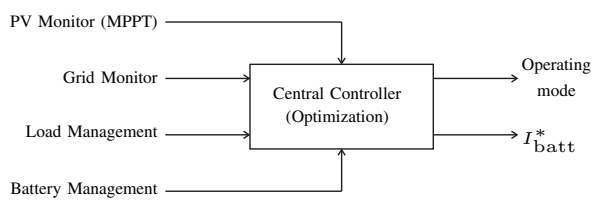

Fig. 5. Concept of management and control for the DSH inverter.

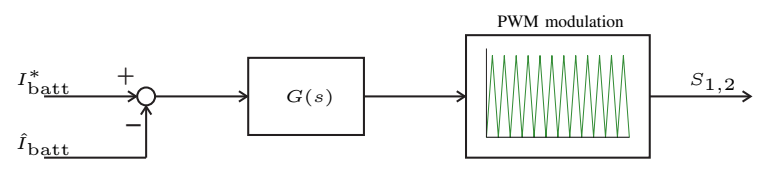

Fig. 6. Current control scheme for the dc/dc converter unit.

Fig. 5 shows an example of how to integrate energy management into a central controller for the DSH inverter. The conditions of PV (including MPPT), grid, load and battery are monitored and managed by an optimization algorithm to determines the operating modes (grid-connected or off-grid) for the DSH inverter and the charge/discharge schedule of the battery [27], [28], so that the system can maximize local renewable energy consumption or optimize the operating cost of the PV storage system. The battery state of charge (SoC) is controlled via the battery current reference $I_{\text {batt }}^{*}$ which influences the operation of the dc/dc converter unit $S_{1}-S_{2}$ (battery charger).

Fig. 6 shows a simple current control block for the dc/dc converter unit. A PI controller $G(s)$ adjusts the battery current to meet its reference $I_{\text {batt }}^{*}$ via PWM signals to $S_{1}-S_{2}$. The reference $I_{\text {batt }}^{*}$ can be positive during charging cycle or negative to discharge the battery. The central controller may disable the dc/dc converter to let the battery current go through diode $D_{1}$ and directly connect to the variable dc link, e.g. when operating at night.

Fig. 7 illustrates a simple voltage control block diagram of the proposed DSH inverter. The capacitor voltage $v_{\mathrm{C} 2}$ is controlled to meet its reference value $V_{\mathrm{C} 2}^{*}$, which is slightly

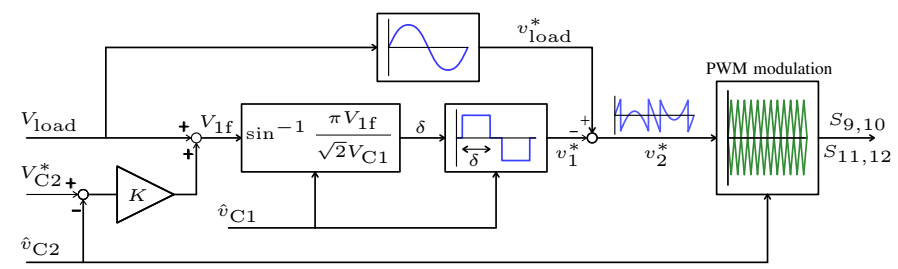

Fig. 7. Voltage control of the smart hybrid inverter in off-grid mode. 
higher than the theoretical value shown in Fig. 4 due to realistic ripple on the capacitor $C_{2}$ during operation. A proportional gain $K$ is applied to estimate the needed fundamental rms voltage $V_{1 \mathrm{f}}$, which is then used to find $\delta$ according to (6), and thus determine the switching patterns of $S_{3}-S_{8}$ to create the rectangular waveform $v_{1}$ at the line frequency. After that, the reference value $v_{2}^{*}$ is calculated based on (9) and used for PWM generation in $S_{9}-S_{12}$. A three-level PWM method is adopted to reduce the effective switching frequency. Then, the switching ripples is filtered out by the LC filter, creating a near sinusoidal output at the load terminals. Here, a bus swing technique can be adopted to reduce the THD of the output current [29], [30].

\section{Simulation WaVEForms}

\section{A. Circuit parameters}

TABLE I

CIRCUIT PARAMETERS.

\begin{tabular}{|c|c|c|}
\hline \multicolumn{3}{|c|}{$\mathrm{dc} / \mathrm{dc}$ converter unit } \\
\hline operating frequency & $f_{\mathrm{sw} 1}=20 \mathrm{kHz}$ & \\
\hline switching devices & $S_{1}, S_{2}$ & IKW30N65H5 \\
\hline dc inductor & $L_{1}=1000 \mu \mathrm{H}$ & $E S R=250 \mathrm{~m} \Omega$ \\
\hline battery & $V_{\text {batt }}=225 \mathrm{~V}$ & nominal value \\
\hline \multicolumn{3}{|c|}{ HERIC unit } \\
\hline operating frequency & $f_{0}=50 \mathrm{~Hz}$ & \\
\hline switching devices & $S_{3}-S_{8}$ & IXFB150N65X2 \\
\hline dc capacitor & $C_{1}=920 \mu \mathrm{F}$ & $\begin{array}{l}\text { EZP-E50107MTA } \\
\text { ALS70A821DF550 }\end{array}$ \\
\hline \multicolumn{3}{|c|}{ active filter unit } \\
\hline operating frequency & $f_{\mathrm{sw} 2}=20 \mathrm{kHz}$ & \\
\hline switching devices & $S_{9}-S_{12}$ & IKW30N65H5 \\
\hline dc capacitor & $C_{2}=920 \mu \mathrm{F}$ & $\begin{array}{l}\text { EZP-E50107MTA } \\
\text { ALS70A821DF550 }\end{array}$ \\
\hline ac inductor & $L_{\mathrm{f}}=200 \mu \mathrm{H}$ & $E S R=50 \mathrm{~m} \Omega$ \\
\hline ac capacitor & $C_{\mathrm{f}}=4.7 \mu \mathrm{F}$ & B32774P6475K000 \\
\hline
\end{tabular}

The performance of the DSH inverter is carried out with circuit simulation. Table I shows the circuit parameters used for the simulation. DC link capacitors $C_{1}$ and $C_{2}$ are chosen so that the voltage ripples are limited to $10 \%$ of the rated ones. In order to reduce capacitor loss, they are made by paralleling a $100 \mu \mathrm{F}$ film capacitor and $820 \mu \mathrm{F}$ electrolytic capacitor. Inductor $L_{1}$ is modelled to limit the current ripple to $\pm 20 \%$ of its rated value. Filter $L_{f}, C_{f}$ are chosen to obtain an output voltage with THD below $5 \%$. The battery voltage is chosen to be $225 \mathrm{~V}$, half of the maximum dc link voltage $V_{\mathrm{C} 1}$ and close to the minimal requirement of $223 \mathrm{~V}$ according to (7). Those parameters are used for preliminary study only and are not yet optimized.

\section{B. Various operating modes}

As the central controller monitors the whole system, the DSH inverter needs to be able to perform power flow control among PV, battery and load/grid, including MPPT. This session reveals the operating waveforms of the the DSH inverter in off-grid mode, supplying power to a $3-\mathrm{kW}$ resistive load.

Fig. 8(a) illustrates the operation of the DSH inverter at night when PV energy is not available. The battery provides

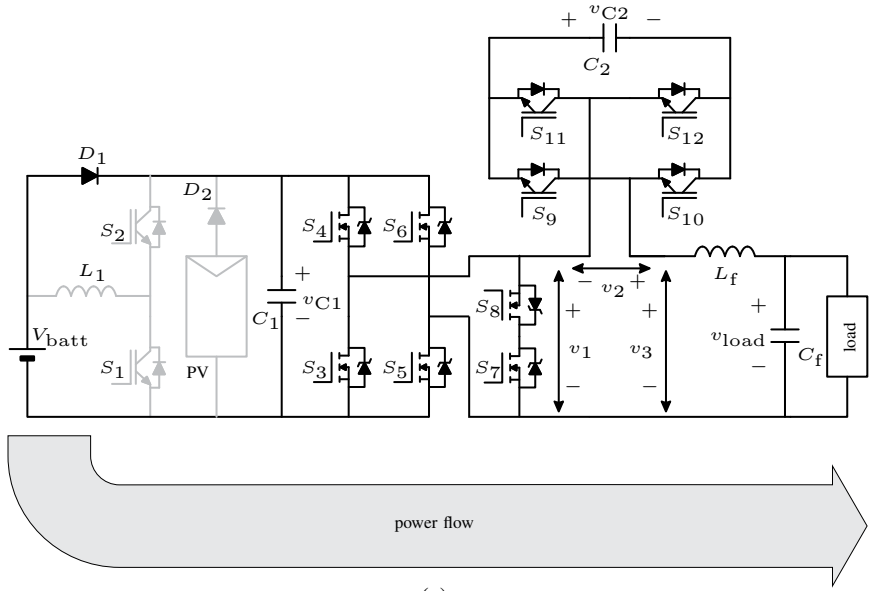

(a)
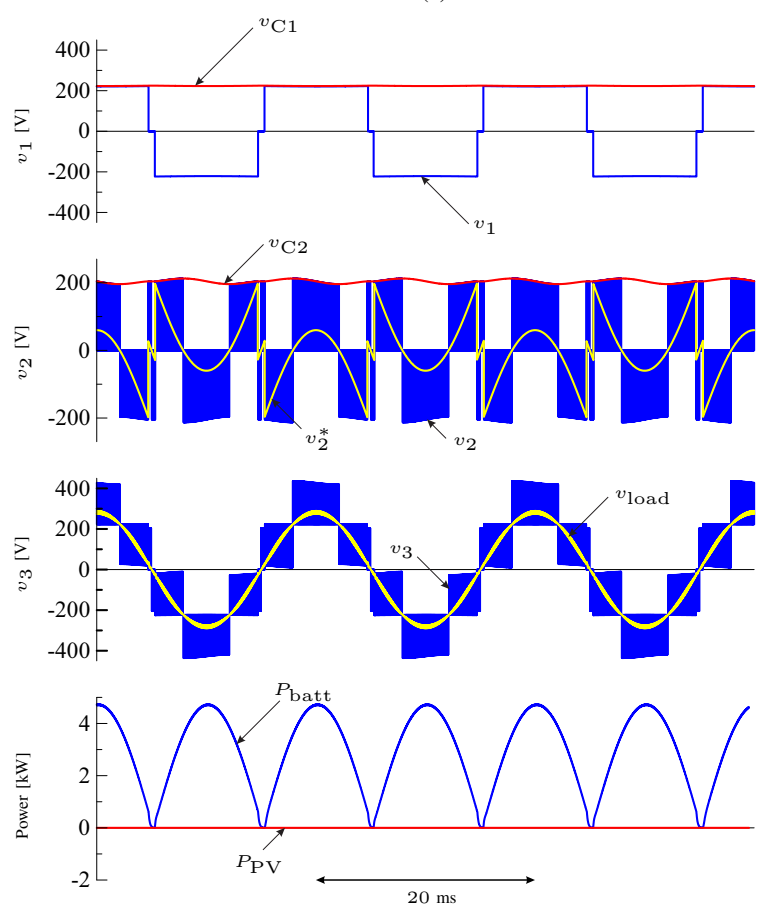

(b)

Fig. 8. DSH inverter operation at night, when only battery provides power to load: (a) circuit operation including power flow, and (b) its simulated waveforms.

power directly to the dc link, resulting in a significant loss reduction because the $\mathrm{dc} / \mathrm{dc}$ converter stage is bypassed via diode $D_{1}$. Fig. 8(b) shows its waveforms during night operation. Since the battery voltage is near the limit $223 \mathrm{~V}$, the pulse width $\delta$ is almost full at $100 \%$. There is almost no fluctuation at $C_{1}$ because it is connected directly to the battery. Therefore, the battery power is determined by the load condition, i.e. 3 $\mathrm{kW}$ and its ac power behaviour with a $100-\mathrm{Hz}$ fluctuation.

When there is enough sunlight, the PV panel will kick in and support a part of the load power as shown in Fig. 9(a). Due to the direction of the power flow in the $\mathrm{dc} / \mathrm{dc}$ converter, only $S_{1}$ is operated, while $S_{2}$ is turned off and thus its anti-parallel diode conducts. In Fig. 9(b), the battery charger performs MPPT to maximize the PV output and thus 


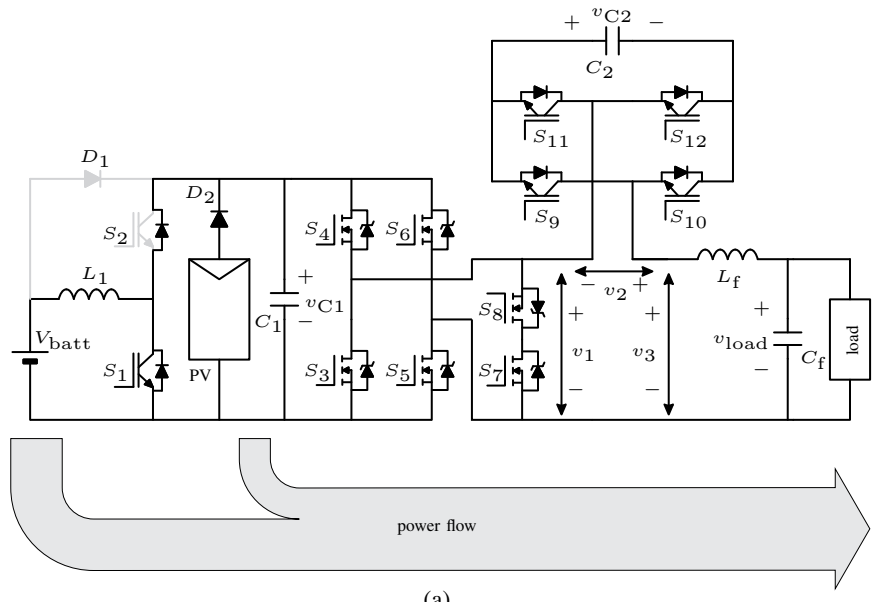

(a)
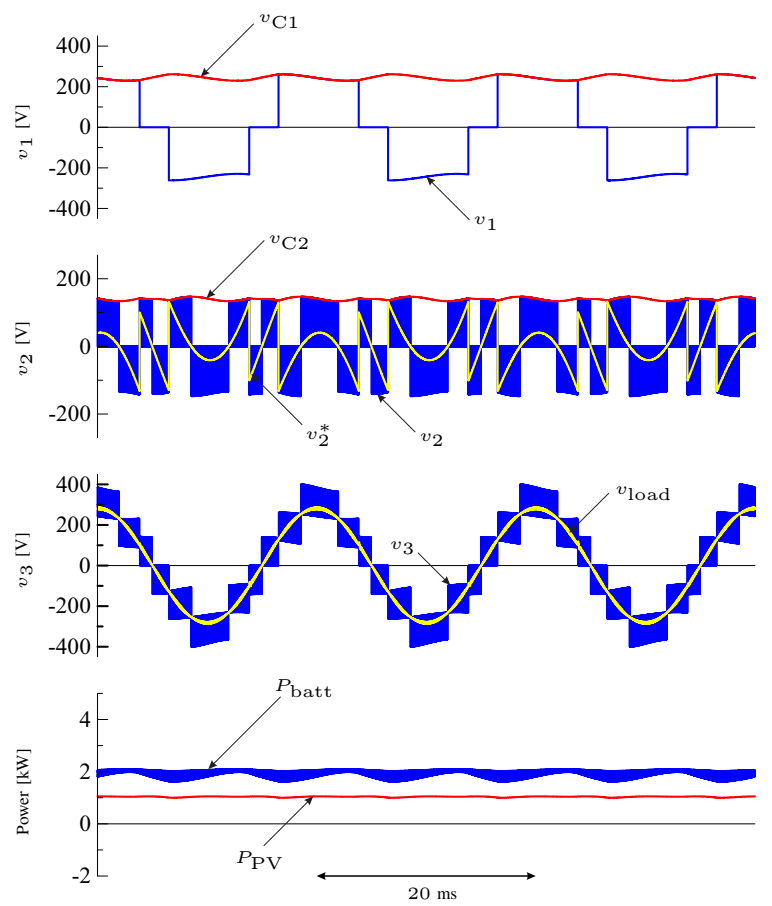

(b)

Fig. 9. DSH inverter operation under weak sun light, where both PV and battery supply power to the load: (a) circuit operation including power flow, and (b) its simulated waveforms.

boost the voltage $v_{\mathrm{C} 1}$ higher to the optimal position of the PV panel, which is around $250 \mathrm{~V}$. At this input voltage level, the voltage $v_{\mathrm{C} 2}$ was controlled to meet its minimal reference value of approximately $140 \mathrm{~V}$ according to Fig. 4. The $100-\mathrm{Hz}$ fluctuation in load power now reflects on the capacitor voltage $v_{\mathrm{C} 1}$.

When the PV panel has enough power to support the load, the battery does not need to provide power anymore and the boost converter is shut down as shown in Fig. 10(a). Another possibility is that the PV power could be more than what the load needs, but the battery is already full. Therefore, the battery power is zero and the PV power provides $3 \mathrm{~kW}$, equal to the load consumption as shown in Fig. 10(b). MPPT operation is not needed in this case unless the grid-connected

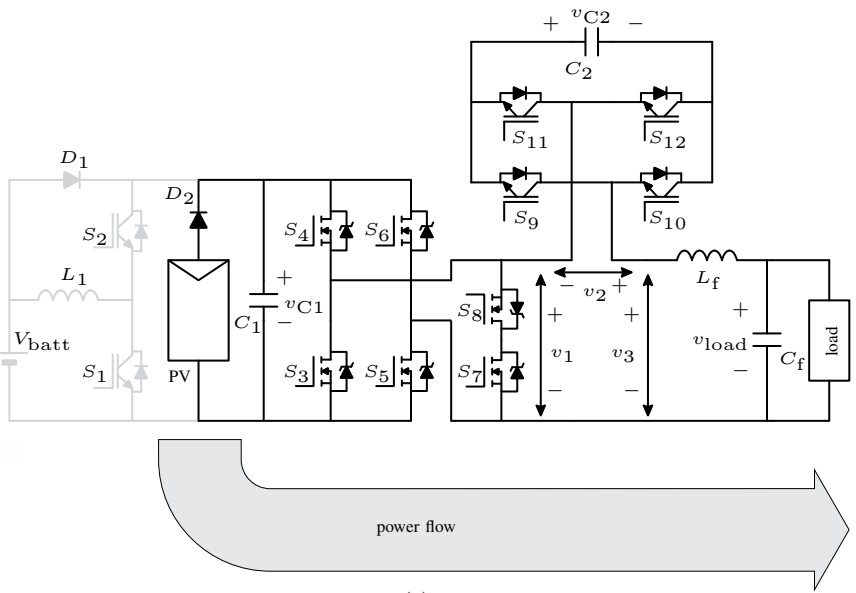

(a)
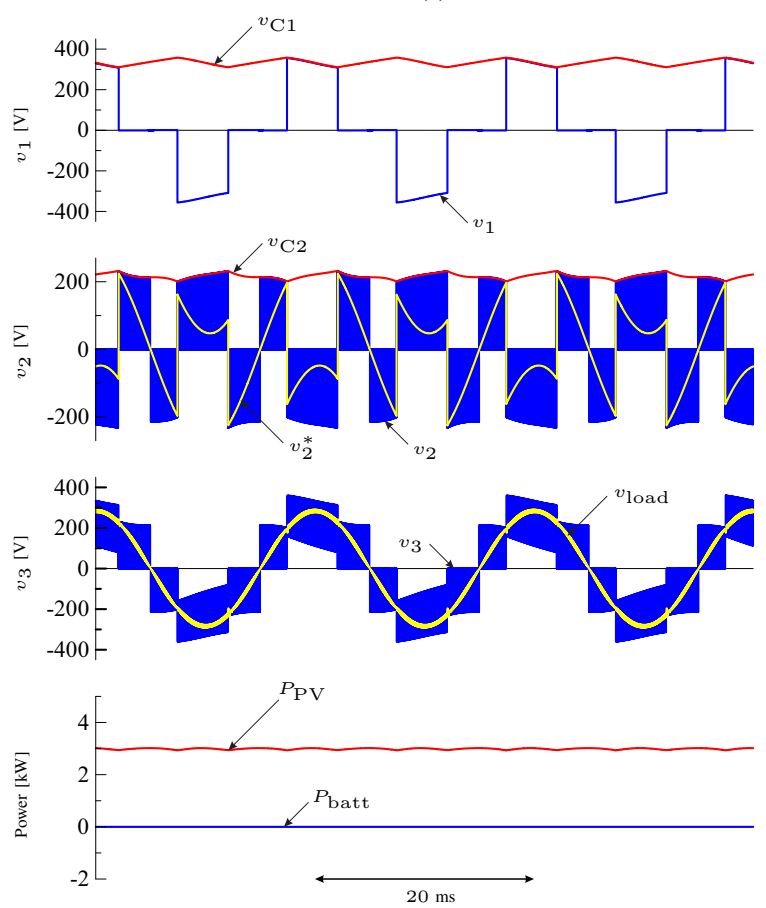

(b)

Fig. 10. DSH inverter operation when PV power is sufficient and battery storage is not in operation: (a) circuit operation including power flow, and (b) its simulated waveforms.

mode is enabled so that the excess PV power can be sent to the grid.

Under strong sun light, the excess solar energy can be used to charge the battery when its SoC is not full as shown in Fig. 11(a). The battery charger operates as a buck converter with $S_{2}$ performs switching while $S_{1}$ is off and its anti-parallel diode conducts. In Fig. 11(b), the MPPT brings the voltage $v_{\mathrm{C} 1}$ higher to a new optimal position of the PV panel. Since the battery is charged, its power becomes negative. Because the capacitor voltage $v_{\mathrm{C} 2}$ in the active filter reaches a higher value when the input voltage is near $450 \mathrm{~V}$ as explained by Fig. 4, this case has the highest output ripple on $v_{3}$ and hence the design of passive filters $L_{\mathrm{f}}, C_{\mathrm{f}}$ had to consider this case as the worst scenarios. 


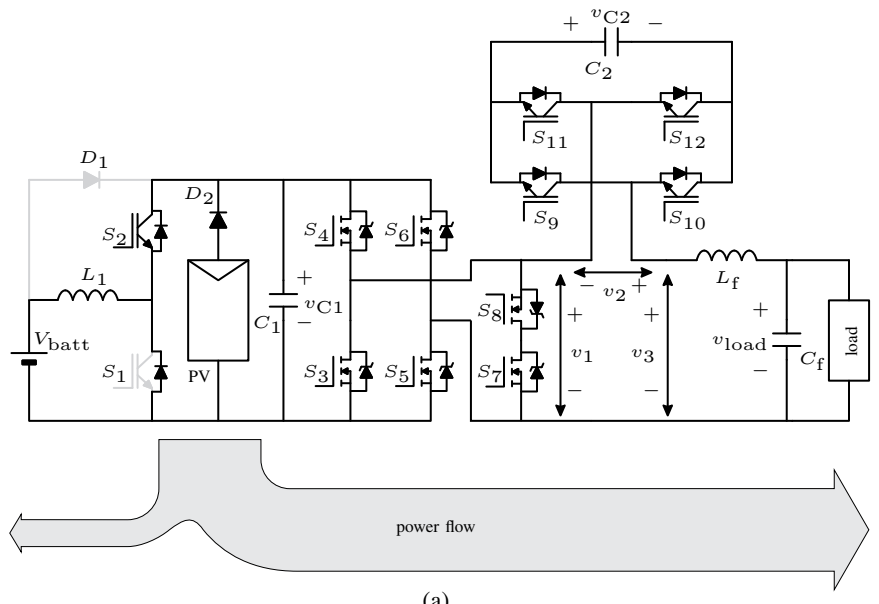

(a)
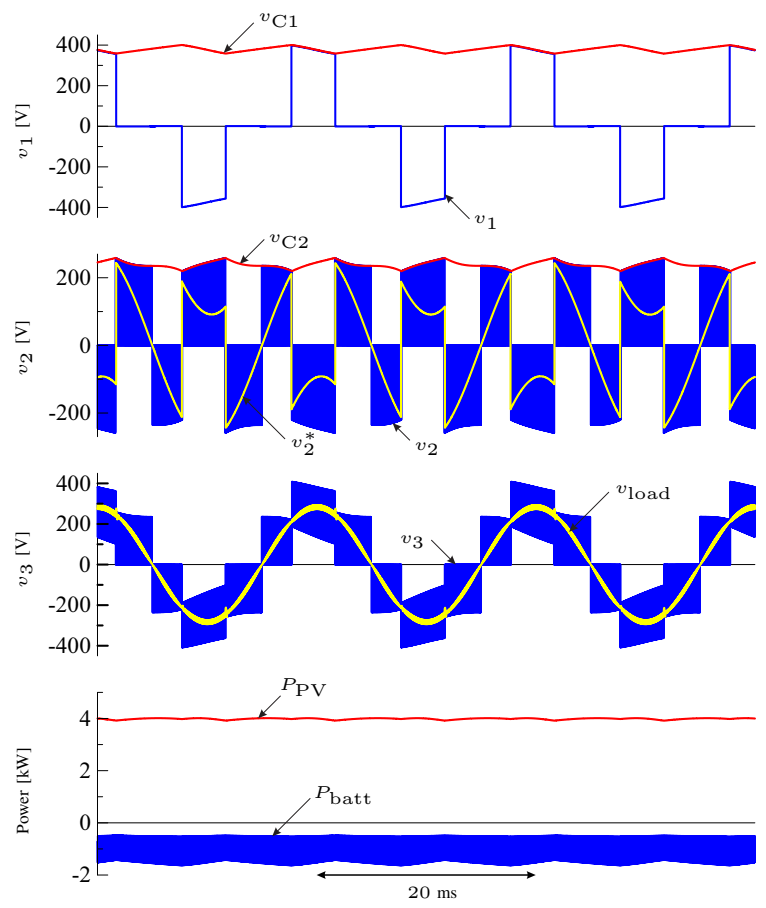

(b)

Fig. 11. DSH inverter operation under strong sun light, battery stores the excess energy: (a) circuit operation including power flow, and (b) its simulated waveforms.

\section{PERformance AnAlysis}

\section{A. Loss calculation}

The loss analysis is based on the available data sheets of the circuit parameters. All switching devices are assumed to operated at the worst case junction temperature of $T_{\mathrm{j}}=150^{\circ} \mathrm{C}$. The IGBTs are driven by a recommended gate resistance $R_{\mathrm{G}}=23 \Omega$. The IGBT switching performance is estimated by PLECS simulation with the switching and conduction losses given by the available measurement given in its data sheet and interpolation method.

Among $S_{3}-S_{8}$ in the HERIC unit, there are always two MOSFETs conducting at a time, thus the conduction loss of

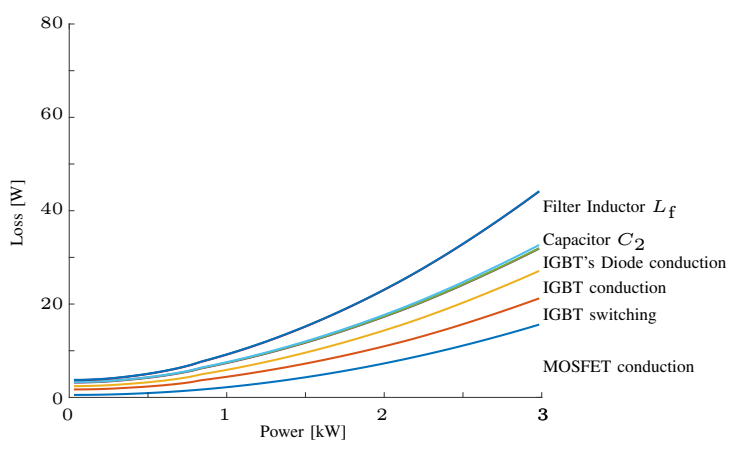

(a)

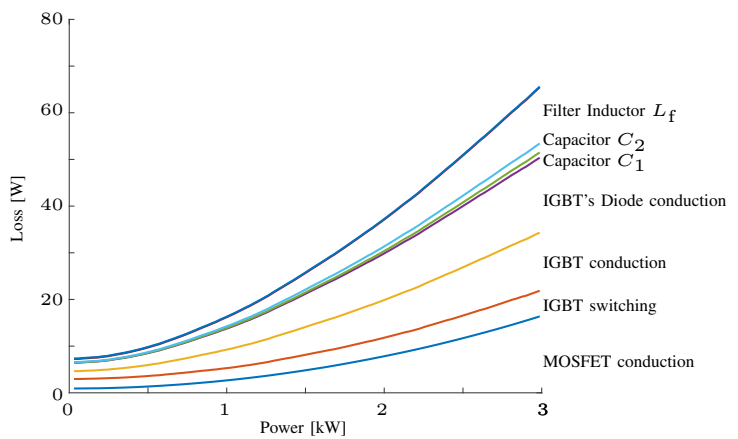

(b)

Fig. 12. Loss breakdown of the DSH inverter: (a) at night when $V_{\mathrm{C} 1}=225$ $\mathrm{V}$, and (b) under strong sun light when $V_{\mathrm{C} 1}=450 \mathrm{~V}$.

all MOSFETs can be expressed by

$$
P_{\mathrm{MOSFET}}=2 R_{\mathrm{DS}(\mathrm{on})} I_{\mathrm{Lf}}^{2},
$$

where $R_{\mathrm{DS} \text { (on) }}$ is the estimated worst case on-resistance of the MOSFETs at $150^{\circ} \mathrm{C}$, and $I_{\mathrm{Lf}}$ is the rms current going through the filter inductor $L_{\mathrm{f}}$ connected in series with the HERIC unit. The switching loss of the MOSFETs is neglected due to the low switching frequency.

The losses in the inductors are considered as their conduction losses only, assuming the resistance given by Table I. The loss in the dc capacitors is similarly defined as

$$
P_{\text {loss }}=E S R \times I_{\text {ripple }}^{2}
$$

where $E S R$ is the worst case equivalent series resistance of the film capacitor and $I_{\text {ripple }}$ is the capacitor rms ripple current. According to the data sheet, it is 2.5 times the typical ESR and equals $12 \mathrm{~m} \Omega$. Since most of the ripple current passes through the film capacitor, the loss in the electrolytic capacitor can be neglected. Finally, the loss in the ac capacitor $C_{\mathrm{f}}$ is also calculated in a similar way but results in negligible value.

This simple loss estimation does not include ohmic loss, auxiliary devices such as controller and gate drivers. The diodes $D_{1}$ and $D_{2}$ are not considered for loss calculation because they can be replaced by mechanical switches with negligible loss. However, even if they are taken into account, a voltage drop of approximately $1 \mathrm{~V}$ will appear and thus result in an efficiency drop of less than $0.4 \%$. 


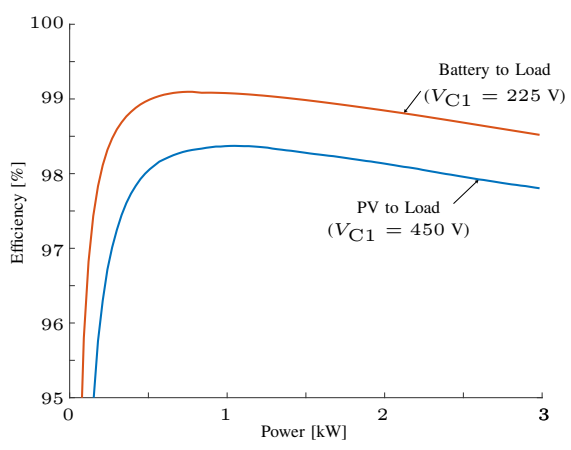

Fig. 13. Efficiency of the DSH inverter.

\section{B. Performance of the inverter}

The key performance of the DSH inverter depends on the HERIC structure and the active AC filter as they are used by both the PV and battery to support the load/grid.

Fig. 12 shows the loss breakdown of the DSH inverter when the input voltage to HERIC unit, $v_{\mathrm{C} 1}$ takes the lowest and highest values. It can be seen that the MOSFET loss are almost the same because the output currents to the load are similar in both cases. However, because the active filter needs to operates at higher voltage under strong sunlight, its losses become higher. It is also noted that the capacitor losses are very small. The only significant loss in capacitor is in $C_{2}$ where the active filter operates at high frequency.

The efficiency of the DSH inverter is estimated to be higher than $98 \%$ when operating at night, approximately $1 \%$ higher than the operation in strong sun light condition where the dc link voltage is highest as shown in Fig. 13. Since the battery is the most expensive component in the system, the superior performance during night mode operation presents a clear benefit because the energy stored inside the battery at night is considered more valuable compared to the abundant PV energy during the day.

\section{Performance of the dc/dc converter}

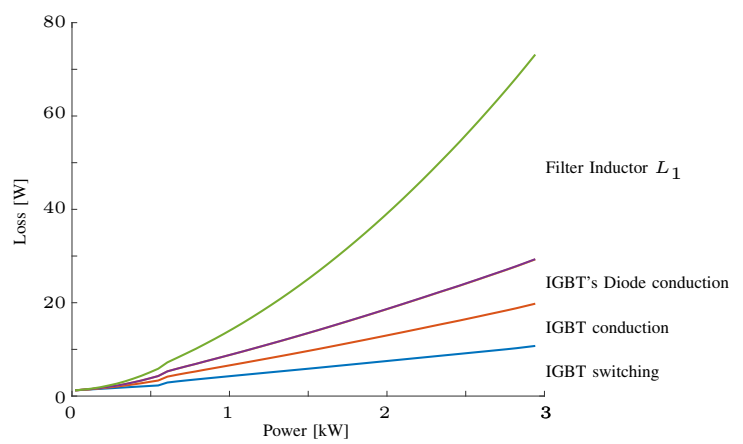

Fig. 14. Loss breakdown of the dc/dc converter, at $V_{\mathrm{C} 1}=450 \mathrm{~V}$.

The dc/dc converter or battery charger has a similar performance in charging and discharging modes in case of boosting ratio equals 2 . Here, the duty cycle of $S_{1}$ and $S_{2}$ is around $50 \%$. Fig. 14 shows the loss breakdown of the battery charger unit when the dc link voltage, $v_{\mathrm{C} 1}$, takes the highest values of $450 \mathrm{~V}$, twice of the battery voltage. If $v_{\mathrm{C} 1}$ is lower than

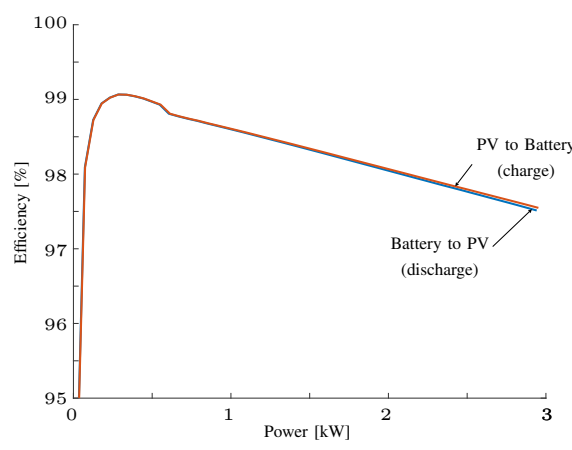

Fig. 15. Efficiency of the dc/dc converter at $V_{\mathrm{C} 1}=450 \mathrm{~V}$.

$450 \mathrm{~V}$, the loss will be lower because of lower voltage stress and lower current ripple, hence this is the worst case analysis of the battery charger. It can be seen that there is a sudden increase in IGBT switching loss when battery power reaches $600 \mathrm{~W}$. This is due to a change from discontinuous conduction mode (DCM) to continuous conduction mode (CCM) where the IGBT receives extra turn-on loss.

It can be seen that the semiconductor and passive losses rise fast and become more than $70 \mathrm{~W}$ in total at the rated power. This results in rather low efficiency of around $97 \%$ at $3 \mathrm{~kW}$ as shown in Fig. 15. On the other hand, the efficiency of the battery charger can be $98 \%-99 \%$ when operating at medium-low power range. For very low power operation where the efficiency drop sharply, burst mode can be applied to bring the efficiency to the peak value of $99 \%$. Although the losses in charging and discharging operations are similar, there is still a small difference appeared in the calculated efficiency because the battery power changed from output to input.

This peak performance at low power actually indicates a good design because it is important that the battery can charges efficiently at low power when solar energy is lacking, e.g. during winter time. On the other hand, when the solar energy is abundant, most of the solar energy will be fed into the grid at low price [6]. Moreover, this path does not involve the battery charger. Therefore, the charger operation at high power is not as important and hence, can be set to a low priority when designing the system or even ignored. In fact, it is acceptable to adopt a dc/dc converter with a lower power rating to save cost without affecting the ability of the DSH inverter of supporting a $3-\mathrm{kW}$ load at night.

\section{Throughput efficiency}

After storing solar energy during the day with the efficiency of $>98 \%$ due to medium-low power operation of the battery charger as shown in Fig. 15, the battery bypasses the dc/dc stage and discharges at night to support the load via the inverter unit and the active filter as explained in Fig. 8(a). During this operating mode, the majority efficiency from battery to load is still higher than $98 \%$ as shown in Fig. 13 . Therefore the throughput efficiency of the whole path PVbattery-load is estimated to be higher than $98 \% \times 98 \%=96 \%$. 


\section{CONCLUSION}

This paper proposed a new concept of single-phase intelligent hybrid inverter called Direct Storage Hybrid (DSH) inverter which can optimize the throughput path of a battery storage. Simulation results demonstrated the feasibility of the DSH inverter, showing stable operations under various $\mathrm{PV}$ conditions. It was proven that the DSH inverter has the potential to achieve a very good throughput efficiency of $96 \%$ or more. This superior performance is particular important to maximize the local consumption, reduce grid dependency, and increase benefits for PV-battery system at residential households.

\section{REFERENCES}

[1] M. A. A. Pedrasa, T. D. Spooner and I. F. MacGill, "Coordinated Scheduling of Residential Distributed Energy Resources to Optimize Smart Home Energy Services," IEEE Trans. Smart Grid, vol. 1, no. 2, pp. 134-143, Sept. 2010.

[2] J. Y. Kim et al., "Cooperative Control Strategy of Energy Storage System and Microsources for Stabilizing the Microgrid during Islanded Operation," IEEE Trans. Power Electron.,, vol. 25, no. 12, pp. 3037-3048, Dec. 2010.

[3] J. Tant, F. Geth, D. Six, P. Tant and J. Driesen, "Multiobjective Battery Storage to Improve PV Integration in Residential Distribution Grids," IEEE Trans. Sustain. Energy, vol. 4, no. 1, pp. 182-191, Jan. 2013.

[4] R. Shah, N. Mithulananthan and K. Y. Lee, "Large-Scale PV Plant With a Robust Controller Considering Power Oscillation Damping," IEEE Trans. Energy Conversion, vol. 28, no. 1, pp. 106-116, March 2013.

[5] D. Velasco de la Fuente, C. L. Trujillo Rodrguez, G. Garcer, E. Figueres and R. Ortega Gonzalez, "Photovoltaic Power System With Battery Backup With Grid-Connection and Islanded Operation Capabilities," IEEE Trans. Ind. Electron., vol. 60, no. 4, pp. 1571-1581, April 2013.

[6] "TEP to buy solar power at under 3 cents per kWh," PV Magazine, May 25, 2017, Online: https://www.pv-magazine.com/2017/05/25/tep-to-buysolar-power-at-under-3-cents-per-kwh/

[7] K. S. Tam and S. Rahman, "System performance improvement provided by a power conditioning subsystem for central station photovoltaic-fuel cell power plant," IEEE Trans. Energy Conversion, vol. 3, no. 1, pp. 64-70, Mar 1988.

[8] S. Daher, J. Schmid and F. L. M. Antunes, "Multilevel Inverter Topologies for Stand-Alone PV Systems," IEEE Trans. Ind. Electron., vol. 55, no. 7, pp. 2703-2712, July 2008

[9] S. V. Araujo, P. Zacharias, and R. Mallwitz, "Highly efficient single-phase transformerless inverters for grid-connected photovoltaic systems," IEEE Trans. Ind. Electron., vol. 57, no. 9, pp. 31183128, Sep. 2010.

[10] H. Qian, J. Zhang, J. S. Lai and W. Yu, "A high-efficiency grid-tie battery energy storage system," IEEE Trans. Power Electron.,, vol. 26, no. 3, pp. 886-896, March 2011.

[11] D. Debnath and K. Chatterjee, "Solar photovoltaic-based stand-alone scheme incorporating a new boost inverter," IET Power Electron., vol. 9, no. 4, pp. 621-630, March 2016.

[12] K. N. Reddy and V. Agarwal, "Utility interactive hybrid distributed generation scheme with compensation feature," IEEE Trans. Energy Conversion, vol. 22, no. 3, pp. 666-673, Sep. 2007.

[13] S. Jain and V. Agarwal, "An integrated hybrid power supply for distributed generation applications fed by nonconventional energy sources," IEEE Trans. Energy Conversion, vol. 23, no. 2, pp. 622-631, Jun. 2008.

[14] M. Das and V. Agarwal, "Novel High-Performance Stand-Alone Solar PV System With High-Gain High-Efficiency DCDC Converter Power Stages," IEEE Trans. Ind. Apps., vol. 51, no. 6, pp. 4718-4728, Nov.-Dec. 2015.

[15] T. V. Thang, A. Ahmed, C. i. Kim and J. H. Park, "Flexible System Architecture of Stand-Alone PV Power Generation With Energy Storage Device," IEEE Trans. Energy Conversion, vol. 30, no. 4, pp. 1386-1396, Dec. 2015.

[16] K. Y. Lo, Y. M. Chen and Y. R. Chang, "Bidirectional Single-Stage GridConnected Inverter for a Battery Energy Storage System," IEEE Trans. Ind. Electron., vol. 64, no. 6, pp. 4581-4590, June 2017
[17] J. Liu, S. Jiang, D. Cao and F. Z. Peng, "A Digital Current Control of Quasi-Z-Source Inverter With Battery," IEEE Trans. Ind. Info., vol. 9, no. 2, pp. 928-937, May 2013.

[18] Y. Liu, B. Ge, H. Abu-Rub and F. Z. Peng, "Control System Design of Battery-Assisted Quasi-Z-Source Inverter for Grid-Tie Photovoltaic Power Generation," IEEE Trans. Sustainable Energy, vol. 4, no. 4, pp. 994-1001, Oct. 2013.

[19] B. Ge, H. Abu-Rub, F. Z. Peng, Q. Lei, A. T. de Almeida, F. J. T. E. Ferreira, D. Sun, and Y. Liu, "An energy-stored quasi-Z-source inverter for application to photovoltaic power system," IEEE Trans. Ind. Electron., vol. 60, no. 10, pp. 4468-4481, Oct. 2013.

[20] M. Amirabadi, H. A. Toliyat and W. C. Alexander, "A Multiport AC Link PV Inverter with Reduced Size and Weight for Stand-Alone Application," IEEE Trans. Ind. Apps., vol. 49, no. 5, pp. 2217-2228, Sept.-Oct. 2013.

[21] C. M. Young, N. Y. Chu, L. R. Chen, Y. C. Hsiao and C. Z. Li, "A Single-Phase Multilevel Inverter With Battery Balancing," IEEE Trans. Ind. Electron., vol. 60, no. 5, pp. 1972-1978, May 2013.

[22] S. S. Lee, B. Chu, N. R. N. Idris, H. H. Goh and Y. E. Heng, "SwitchedBattery Boost-Multilevel Inverter with GA Optimized SHEPWM for Standalone Application," IEEE Trans. Ind. Electron., vol. 63, no. 4, pp. 2133-2142, April 2016.

[23] H. Schmidt, S. Christoph, and J. Ketterer, "Current inverter for direct/alternating currents, has direct and alternating connections with an intermediate power store, a bridge circuit, rectifier diodes and a inductive choke," Patent DE10221592 A1, Dec. 4, 2003.

[24] A. Iwata, H. Ito, H. Akagi, H. Fujita, and T. Jimichi, "Power converting apparatus including half-bridge inverters connected between positive and negative terminals of a DC power supply," Patent US 8228699 B2, 2008

[25] H. Fujita, "A high-efficiency solar power conditioner using a zigzagconnected chopper converter," The 2010 International Power Electronics Conference - ECCE ASIA -, Sapporo, 2010, pp. 1681-1687.

[26] M. Chen, K. K. Afridi and D. J. Perreault, "A Multilevel Energy Buffer and Voltage Modulator for Grid-Interfaced Microinverters," IEEE Trans. Power Electron.,, vol. 30, no. 3, pp. 1203-1219, March 2015.

[27] Bo Lu and M. Shahidehpour, "Short-term scheduling of battery in a grid-connected PV/battery system," IEEE Trans. Power Systems, vol. 20, no. 2, pp. 1053-1061, May 2005.

[28] M. Pereira, D. Limon, D. Muoz de la Pea, L. Valverde and T. Alamo, "Periodic Economic Control of a Nonisolated Microgrid," IEEE Trans. Ind. Electron., vol. 62, no. 8, pp. 5247-5255, Aug. 2015.

[29] A. Giustiniani, G. Petrone, G. Spagnuolo and M. Vitelli, "LowFrequency Current Oscillations and Maximum Power Point Tracking in Grid-Connected Fuel-Cell-Based Systems," IEEE Trans. Ind. Electron., vol. 57, no. 6, pp. 2042-2053, June 2010.

[30] J. M. Galvez and M. Ordonez, "Swinging Bus Operation of Inverters for Fuel Cell Applications With Small DC-Link Capacitance," IEEE Trans. Power Electron., vol. 30, no. 2, pp. 1064-1075, Feb. 2015. 